\title{
Enhancing Multicultural Awareness: Understanding the Effect of Community Immersion Assignments in An Online Counseling Skills Course
}

\author{
Valerie G. Couture ${ }^{1}$ \\ ${ }^{1}$ Department of Leadership Studies, College of Education, University of Central Arkansas, United States \\ Correspondence: Valerie G. Couture, Leadership Studies Department, University of Central Arkansas, 201 Donaghey \\ Avenue, Mashburn Hall 220, Conway, AR 72035, United States. https://orcid.org/0000-0002-4438-0194
}

Received: April 23, 2021

Accepted: May 20, 2021

Online Published: May 21, 2021

doi:10.5430/ijhe.v10n5p201

URL: https://doi.org/10.5430/ijhe.v10n5p201

\begin{abstract}
Counselor education programs provide counselors-in-training (CITs) with courses focused on counseling skill development to increase the CITs' interpersonal counseling abilities and increase multicultural awareness. The research study presents findings from the author's exploration of online students' experiences in an experiential community immersion assignment. For analysis, the data was divided into three timeframes: (a) pre-experience, (b) active-experience, and (c) post-experience. In the pre-experience timeframe two themes emerged: (a) overwhelming nervousness and (b) judgmental thoughts. In the active-experience timeframe two themes emerged: (a) welcoming environment and (b) normalization of the minority population. During the post-experience reflections three common themes emerged: (a) similarities between groups, (b) motivation to create relationships, and (c) increased empathy. The study concluded the participants reported an overall increase in multicultural awareness through their community immersion experiences.
\end{abstract}

Keywords: counselor education, online learning, counseling, experiential, multicultural, diversity

\section{Introduction}

The number of counselor education programs that use online teaching methods is continually increasing (Cicco, 2013; Oswald, Huber, Wilson, \& Embree, 2015). Due to the increase in technological advances and competition for students, many colleges and universities are building online components to their on- campus coursework. In graduate level counselor education programs such as school counseling, clinical mental health counseling, and rehabilitation counseling, students take courses that assist in the development of basic counseling skills. The topics covered in a basic counseling skills course are interpersonal in nature. These topics typically include body language awareness, building rapport, establishing trust, diversity issues, and creating a warm, empathic environment. When an instructor attempts to teach these interpersonal topics in a virtual classroom it can be challenging for both the instructor and the student given the class meetings are not face-to-face (Irvine \& Carmichael, 2009; Ivey, Ivey, \& Zalaquett, 2010). Even though teaching interpersonal skills in an online environment is challenging, it is imperative that CITs are able to receive ample preparation for their future profession (Cicco, 2013; Yang \& Chou, 2008). It is also important that students build awareness of the diversity of clients they will see in their future employment within schools and community agency settings.

Given the importance of building counselors with solid counseling skills and multicultural awareness, the author conducted a study of CITs' experiences while in an experiential community immersion project. The goal of this study was to understand the experiences of online CITs as they went into their local communities to determine if counseling skill development and multicultural awareness increased. This research is critical to exploring the teaching methods counselor educators can use to ensure their online students will gain the experiences necessary to work with diverse populations effectively.

The researcher examined the current literature to understand how educators were combining online education with experiential education for increasing basic counseling skills and multicultural counseling competence. In addition, a review of the current expectations of counselors who practice in schools, mental health agencies, and rehabilitation settings was assessed by reviewing the updated codes of ethics published by the national counseling professional 
organizations. Academic journals, whose focus was on online education, counselor education, and experiential education, were reviewed to identify emerging trends regarding teaching methods and learner outcomes.

\section{Review of the Literature}

\subsection{Counselor Skill Development}

Faculty who teach basic counseling skills with graduate students are challenged to create assignments and assessments which will help move students along developmentally to the place where they are competent working with individuals from various backgrounds (Benshoff \& Gibbons, 2011). When the basic counseling skills course is taught using an online format, the instructor must still be able to assess the degree to which students have mastered the material and gained confidence in their abilities to work with diverse people. Through using experiential education assignments, such as service learning and community awareness research, students can gain experiences of working with and learning about diverse people. In Pedagogy in counselor education: A 10-year content analysis of journals, Minton, Morris, and Yaites (2014) reviewed 230 peer-reviewed articles that focused on teaching and learning in counselor education. Their goal was to note the trends over the past 10 years (Minton et al, 2014). One of the trends in counselor education was using experiential activities, such as service learning, as a teaching technique to increase students' interactions with people from different cultures.

\subsection{Multicultural Competencies}

Professional counselors working in schools and community agencies must be able to work respectfully and advocate for clients from all backgrounds. The American School Counselor Association code of ethics (ASCA, 2017) states school counselors must act as social change advocates and should affirm all students from diverse populations including but not limited to: ethnic/racial identity, nationality, age, social class, economic status, abilities/disabilities, language, immigration status, sexual orientation, gender, gender identity/expression, family type, religious/spiritual identity, emancipated minors, wards of the state, homeless youth and incarcerated youth. (p. 1)

Clinical mental health counselors following the American Counseling Association (ACA) code of ethics must work towards becoming multiculturally competent so they can work with individuals from minority backgrounds (ACA, 2015). Multicultural and social justice counseling competencies have been developed to provide professional counselors with a framework to view how identities intersect and issues of power, privilege, and oppression affect the counselor and client relationship (ACA, 2015). Similarly, rehabilitation counselors also must develop knowledge around diversity issues and maintain personal awareness, sensitivity, and skills in order to work competently with diverse client populations (Commission on Rehabilitation Counselor Certification [CRCC], 2017).

\subsection{Experiential Learning Theory}

Students in higher education are typically taught using traditional classroom pedagogical approaches (Nakelet et al., 2017). Students listen to lectures and engage in activities to show they have absorbed the required information (Kolb \& Kolb, 2005). Experiential Learning Theory provides an opportunity for instructors to engage students actively in their own learning (Lachapelle \& Whiteside, 2017). The expectation when a student is engaged in experiential learning is the student is "creating knowledge and critically reflecting on their experiences, allowing them to understand how to transfer their knowledge and skills to future endeavors," (Lachapelle \& Whiteside, 2017, p. 2). A community immersion project, in which the student is required to participate in a community outside of the higher education institution, is a teaching technique which has been used in many fields of study (Sherman \& Boukydis, 2020). Various types of experiential education, such as community immersion projects and service learning activities have been found to build awareness of diversity issues (Sherman \& Boukydis, 2020).

Counselor education programs using community immersion projects in their coursework to enhance the multicultural awareness of students usually require students to interact with marginalized communities. Examples of marginalized communities typically include: racial/ethnic minorities, LGBTQIA-identifying, older populations, homeless, people with disabilities, and religious minorities. One example of a project, completed by Toporek and Worthington (2014), studied graduate counseling students who worked with individuals who were homeless and near homeless on career and employment counseling. The goal of this service learning project was to enhance students' attitudes regarding the homeless population and those living in poverty by allowing the students to engage in conversations with people from this demographic (Toporek \& Worthington, 2014). Gaining a certain level of comfort in working with those who are from a lower socioeconomic class is important for students who wish to become professional counselors. In this country, socioeconomic class is still a taboo subject for many who prefer to believe that the United States was founded on a merit system. Maximizing the students' opportunities to work with people who are marginalized because they have very little money was a goal of the service-learning project. 
Toporek and Washington's (2014) project included pre-service training between the students and the instructors and post-service debriefing as well. Students were aware they would be counseling with individuals who have had barriers to employment including; no phone number, no home, time spent in prison, low education level, limited wardrobe, and limited access to bathing facilities (Toporek \& Worthington, 2014). After meeting with the clients and providing them with career and employment counseling, the students were to write a one-page reflection of their experience (Toporek \& Worthington, 2014). Reflections were to include thoughts, feelings, and reactions to their clients so the graduate students would have a better idea of their own biases and also what they learned about this population that surprised them (Toporek \& Worthington, 2014).

In a similar service-learning project, researchers studied the effect of graduate students working directly with clients who reported being gay, lesbian, or bisexual. From a historical perspective, in the counseling and psychology profession, clients who identified as gay, lesbian, or bisexual have been counseled in ways which were different from clients who identified as heterosexual. In 1973 the "American Psychiatric Association removed homosexuality from the list of diagnoses" that psychologists and therapists could give to a client (Stewart \& Mejia, 2011, p. 301). However, even with removing the diagnosis there remains to this day a stigma attached to those who are gay, lesbian, or bisexual. Stewart et al. (2011) reported that graduate counseling students will spend time learning about diverse populations, but they do not spend much time learning how to interact with diverse populations. Providing opportunities during a semester long class in which part of it is learning how to interact with clients who have different backgrounds (e.g., sexual orientation, religion, ethnicity, and socioeconomic class) will impact students in ways that learning from books cannot.

Burnett, Hamel, and Long (2004) reported a service-learning model that was used in a multicultural counseling course. The "model is based on principles connected to counselor self-awareness (importance of self-in-relation) and peer learning (usefulness of immediate corrective feedback), international exposure (intergroup contact), and community-centered perspectives (cooperative learning based on mutuality)," (Burnett et al., 2004, p. 181). At the conclusion of the course the students overwhelmingly indicated they felt more culturally competent, however, due to the course being a six week summer session, they felt the experience would have been more impactful if they had taken it during a traditional length semester (Burnett et al., 2004).

\subsection{Social Advocacy}

Calls for increased social advocacy work in the counseling profession have existed throughout the years from the ACA (Jett \& Delgado-Romano, 2009). To impart to graduate students the importance of experiencing hands-on social advocacy work for their future work as professional counselors, it has been suggested that requiring students to complete service learning while in school will be the best way to for them to become familiar with the concept of social advocacy (Jett \& Delgado-Romano, 2009).

Smith, Jennings, and Lakhan (2014) studied graduate students who were enrolled in a diversity class that included a service-learning study abroad component. The intent of the service-learning component was for students to develop "cultural competence and awareness of social justice issues through direct contact with diverse groups" (Smith et al, 2014, p. 1) in Singapore. Underutilization of counseling services by populations who are not White has been recorded for many years and one of the reasons indicated is due to counselors' deficiencies in cultural competencies (Smith et al, 2014).

In relation to social advocacy and clinical counseling skills, Burnett et al. (2004) reported that early experiential activities in students' academic plans would allow students to incorporate that learning experience throughout the rest of their studies and into their practicum and internship semesters. Using the first year of academic study to gain comfort with diverse populations before a student completes internships is an ideal way to prepare the student in a more complete way (Burnett et al., 2004).

\subsection{Anxiety Reduction}

Barbee, Scherer, and Combs (2003) reported "an inverse relationship exists between counselor self-efficacy and anxiety" (p. 111). It is common that counseling students will experience anxiety as they are learning about their new profession and the expectations which they will need to follow to be successful (Barbee et al., 2003). A successful counselor is one who stays within the code of ethics, has a positive sense of self-efficacy, and continues to want to learn and apply that knowledge to working with a diverse set of clients.

Faculty who teach in graduate counseling programs should address student anxiety and should have a way that their program tries to reduce the anxiety which will be present in incoming and current students. Experiential education activities can be a helpful tool in reducing anxiety, especially in novice graduate students who have not had much work 
experience with diverse populations. Research shows the positive effect that reducing anxiety has on increasing counselor self-efficacy. Through a quantitative study of 113 graduate counseling students, Barbee et al. (2003) found a "significant difference in self-efficacy between those who took part in service learning versus those who did not engage in service learning" (p. 111). Moreover, "there was a negative correlation between counselor self-efficacy and state anxiety, which was consistent with similar studies" (Barbee et al., 2003, p. 114). Servaty-Seib and Parikh (2014), conducted a study to determine the effect of service learning on graduate students who were enrolled in a group counseling course focusing on death education. Their evaluation indicated students who took a graduate level group counseling course with a service learning component exhibited lower distress in death-related clinical situations than students who took the course without the service component (Servaty-Seib \& Parikh, 2014).

\section{Purpose of Study}

Being able to identify the best practices to build counselor skill development and multicultural awareness in CITs is critical to ensure competent professional counselors. Counselor educators who work in online counseling programs need to evaluate how they are using their assignments to enhance the abilities of their students. Therefore this study sought to use experiential education as a teaching tool with the goal of increasing the multicultural awareness and building counselor skill development of the CITs. The assignment used to gather data is in Appendix A. The following main research question was addressed: What are the experiences of online counselors-in-training while in an experiential community immersion project? In order to further frame the participant responses, three sub-ordinate questions were asked:

1. What are the thoughts and feelings the student is experiencing before the community immersion? (Pre-experience reflections)

2. What are the thoughts and feelings the student is experiencing during the community immersion? (Active-experience reflections)

3. What are the thoughts and feelings the student is experiencing after the community immersion? (Post-experience reflections)

\section{Method}

\subsection{Framework}

The frameworks used for this research study were Experiential Learning Theory and phenomenology, as the goal was to understand the experiences of the students as they participated in an experiential activity. Experiential Learning Theory creates a framework for learning in which the student participates in an experience, reflects on that experience, and formulates ideas to be used in the future (Lewis et. al, 2017). This study sought to understand what the experiences of the students were when they were immersed in a marginalized community that was new to them. A phenomenological framework describes the common meaning for several individuals of the same lived experience (Creswell, 2013). The researcher used procedures for conducting a phenomenological study which provided a systematic way of collecting data and analyzing information (Creswell, 2013).

\subsection{Researcher Positionality}

The lens of the researcher and the lenses of the participants interacted together to create the understanding of the participants' experiences. The researcher is a faculty member in an online counselor educator program at a regional mid-South public university. She identifies as being a cisgender middle-class European-American woman. The researcher recruited the participants and analyzed the data.

\subsection{Trustworthiness Procedure}

Following the best practices of qualitative research, several techniques were engaged in to ensure trustworthiness. Expert external reviewers in counselor education and qualitative research methods were involved in reviewing the experiential community immersion project details to ensure the project guidelines were inline with best practices in education before participants were recruited (Burnett et. al, 2005). After the reflections were analyzed member checking of the data was completed to ensure the analysis adequately represented the participants' perceptions of their lived experiences (Burnett et. al, 2005). The participants believed the analysis accurately reflected their statements and ideas. Saturation was reached with a total of 21 participants involved in the study.

\subsection{Participants}

Participants were recruited from a master's level online Individual and Group Counseling class taught by the researcher. All the participants in the study $(\mathrm{N}=21)$ reported living in either rural or suburban communities in a mid-South state. 
The majority $(n=20)$ of the participants identified as females and the minority $(n=1)$ identified as male. Eighty-six percent $(n=18)$ reported being White for their racial/ethnic group, with nine percent $(n=2)$ reporting being Black, and five percent $(n=1)$ reporting being Latinx. The age range of the participants was from 23 to 42 years old $(m=31)$.

\subsection{Procedure and Data Collection}

The researcher obtained institutional review board approval before starting the study. All of the participants were enrolled in the researcher's graduate level Individual and Group Counseling Skills class. A total of 32 students were invited to participate in the study. While all of the students had the same community immersion assignment, the students had the option to have their reflection papers excluded from the research study. Twenty-one students agreed to participate by turning in the informed consent form and the demographic data sheet, which would allow the researcher to analyze their reflection papers to find common themes.

A copy of the complete assignment is in Appendix A. Due to the majority of the participants identifying as White, cisgendered, and Christian, the researcher gave the following parameters in the assignment. They were to spend time with a multicultural group which they did not have much experience with. The options for a multicultural group were the following categories: (a) Asian Americans, (b) African Americans, (c) Hispanic Americans, (d) Native Americans, (e) religious minorities, (f) refugees, (g) People with Disabilities (PWD), (h) LGBTQIA individuals, or (i) homeless or near homeless individuals. The students were to record their thoughts and feelings during three distinct timeframes: (a) pre-experience, (b) active-experience, and (c) post-experience.

\subsection{Data Analysis}

The phenomenological data was analyzed and interpreted using the Colaizzi seven-step method (1978). This data analysis method is important to identify patterns across the data sets which are consistent to the phenomenon being explored (Colaizzi, 1978). The seven steps of the Colaizzi (1978) method requires the researcher to: (a) repeatedly read the interviews, (b) extract significant statements, (c) formulate meanings for each significant statement, (d) move the meanings into theme clusters, (e) write descriptions for each theme cluster, (f) use member checks to validate descriptions, and (g) identify fundamental structures and relationships between structures.

While the researcher did substitute written documents for interviews, the remaining steps of data analysis were followed. The researcher completed the data analysis steps using the following steps. In step 1, the research read through the documents several times to get a feeling for the content before coding. In step 2, the researcher reread the transcripts and took note of recurring words, phrases, and sentences that became significant statements. In step 3, the recurring words, phrases, and sentences were formulated into meanings for each significant statement. In step 4, the researcher shifted the formulated meanings into clustered themes which were common to all participants. In step 5, exhaustive descriptions for each theme cluster were written. In step 6, the descriptions were validated using member checks. In step 7 , fundamental structures and the relationships between the structures were identified. Themes were identified as outcomes of the study.

\section{Results}

The results reveal the CITs' perspectives of their experiences during the experiential community immersion assignment. Appendix B provides a chart, Figure 1, categorizing the sites the participants chose for their community immersion. For analysis, the data was divided into three timeframes: (a) pre-experience, (b) active-experience, and (c) post-experience. When analyzing the data in each timeframe, themes were identified which were common among the participants. Appendix $\mathrm{C}$ provides a descriptive representation of the findings in Table 1.

\subsection{Research Question 1: What Are the Thoughts and Feelings the Student Is Experiencing before the Community} Immersion? (Pre-Experience Reflections)

Participants were asked to record all thoughts and feelings they had before they began their immersion experience. This part of the study is related to building self-awareness and mindfulness that students in counselor education programs are expected to practice as they are becoming professional counselors. In the pre-experience timeframe two themes emerged: (a) overwhelming nervousness and (b) judgmental thoughts.

\subsubsection{Overwhelming Nervousness}

One hundred percent $(\mathrm{N}=21)$ of the participants reported feelings of overwhelming nervousness in their pre-experience reflections. One participant, "Katelyn" noted, "It makes me very nervous because I will be in the minority. I feel like people may stare at me and wonder what I'm doing there." Another participant, "Glenda" reported, "I was so nervous because I have not been around many people from different races so I was not really sure what to expect." 


\subsubsection{Judgmental Thoughts}

Almost half of the participants $(n=10)$ recorded thinking judgmental thoughts about the community they would be visiting. The thoughts and the reflections about her judgmental thoughts were recorded in this observation from participant, "Sandra,"

I struggle with the homeless. I feel they chose to live on the streets, most refuse services designed to help them, and that they are lazy and do not wish to work or change their life for the better. I am ashamed to actually tell my true feelings.

Another participant who chose to visit a homeless shelter reported, "I expected some of the people to be greedy. I thought the people would be very disrespectful." A third $(n=7)$ of the participants chose to attend a minority religious service. One who attended an African American church service described feeling judgmental beforehand. Participant "Jennifer" reported, "I thought that African Americans were kind of loud and honestly intimidating."

Twenty-eight percent of the participants $(n=6)$ chose to attend a LGBTQIA event, many of which had to drive to a different town. For the participants who chose to participate in a LGBTQIA event, their religious background was reported to be one of the reasons they held judgmental thoughts towards this population of people. Participant "Jalissa" wrote, "Having been raised in a very conservative, Christian home I was taught homosexuality was a sin and should be condemned. I have never believed homosexuality is morally right."

\subsection{Research Question 2: What Are the Thoughts and Feelings the Student Is Experiencing During the Community} Immersion? (Active-Experience Reflections)

During the active-experience timeframe the participants had been asked to be mindful of their thoughts and feelings while they were immersed in the community immersion activity. While it can be difficult to be a part of an activity while also being observant of one's own thoughts and feelings, the participants were able to provide a thoughtful reflection of not only their emotional feelings, but also their physical body sensations as well. In the active-experience timeframe two themes emerged: (a) welcoming environment and (b) normalization of the minority population.

\subsubsection{Welcoming Environment}

The majority of the participants $(n=15)$ reported feeling welcomed by the new community they were entering. Thirty-eight percent $(n=8)$ of the participants worked in a homeless shelter or low-income community resource center. Participant "Amanda" reported that both the shelter workers and the homeless people were "friendly and grateful" when she volunteered her time to serve food. She wrote, "Maybe it was because I had these horrible, very wrong ideas of what these people would be like and they were completely different. They made me feel comfortable." One third of the participants $(n=7)$ visited a minority religious service and all of these participants reported feeling welcomed by the community members. "Everyone was very friendly towards me and made me feel like I belong even though it was clear that I did not," was recorded by participant "Derek." This sentiment was echoed throughout the reflections of the remaining participants who had also visited a minority religious service.

\subsubsection{Normalization of the Minority Population}

The second theme which emerged during the active-experience timeframe was feeling shocked by how normal the population seemed to be once they were immersed. "As I kept walking down the street, I saw many normal families with children having a fun day out," was reported by a participant who attended a LGBTQIA event. Another participant, "Rhonda" reported her experience with the LGBTQIA population "demystified a lot of things for me and made me realize they are just regular people, with regular lives, and regular struggles." Similarly the participants who spent time in a homeless shelter or low-income community resource center recorded thoughts that the community members reminded them of people in their own lives. "I was very comfortable when playing with the little boys but at times I felt my emotions were taking over," was reported by participant "Erin" who acknowledged the "homeless kids were more normal than I had expected."

\subsection{Research Question 3: What Are the Thoughts and Feelings the Student Is Experiencing after the Community} Immersion? (Post-Experience Reflections)

Following the Educational Learning Theory framework, students recorded their reflections after they completed their experiences. Three common themes emerged during the post-experience reflections: (a) similarities between groups, (b) motivation to create relationships, and (c) increased empathy. While there was diversity in the overall three types of community immersion sites chosen; (a) minority religious institutions, (b) LGBTQIA events, and (c) homeless/low-income community resource centers, common themes were found from all the participants. 


\subsubsection{Similarities Between Groups}

The participants noticed how similar they were to the community there were spending time in. The majority of participants $(n=16)$ reflected experiences where they found common ground (hobbies, interests) with people in the community. "Once I got over the initial hump of just getting to the event, I noticed families that were a lot like mine there," noted participant "Jalissa" who attended a Gay Pride event. "Jalissa," who also ended up eating lunch with people who identified as lesbians reported,

"Surprisingly, I didn't feel at all like I thought I would by having lunch with women whose sexual orientation is so different from my own. We actually had a lot in common that we chatted about. I'm so glad I took a chance to get to know them."

All of the participants $(n=7)$ who attended religious minority services had experiences where they found commonality in the way the service progressed from beginning to end, even if the service was in a different language. "While not understanding everything, I was able to follow along with the service, and I noticed some teenagers playing on their cell phones, which I guess happens everywhere. This comforted me," reflected participant "Kim."

\subsubsection{Motivation to Create Relationships}

After the community immersion project, one hundred percent $(\mathrm{N}=21)$ of the participants felt more motivation to create relationships with people who were in the population they were immersed in. One participant "Elizabeth" commented, "Actions speak louder than words. When I begin working as a counselor, I need to be sure to make these poor children feel comfortable and accepted." Another participant "Christina" reflected, "In my role as a school counselor, I hope to be able to build relationships, a partnership with parents and families in poverty." This sentiment was echoed in other responses when the participants had attended a religious minority service. Participant "Glenda" reflected,

"I learned that people can worship differently and doing something differently doesn't mean it is wrong. In fact, in my community, unless you are a card-carrying Christian, you might not be well-liked. I want people from a non-Christian background to know I support them and will have their back and be their friend."

\subsubsection{Increased Empathy}

All the participants $(\mathrm{N}=21)$ noted they felt more empathetic after the experience towards the community they spent time in. Participant "Katie" who attended a minority religious service commented, "I now know what it feels like to be the minority in the room! You feel like everyone is looking at you, when maybe that isn't actually happening, but it is an uncomfortable feeling." "As a school counselor, I would not want to make anybody feel like they can't approach me cause I don't look like them or I don't practice their religion," reflected participant "Glenda." Another participant, "Cindy" who attended an LGBTQIA event, reported increased empathy with "kids who may be trying to figure out who they are and who they love. This isn't always the easiest thing to do if you think you might be gay in my area."

\section{Discussion}

There were limitations of this study. The first limitation was the participants were vulnerable to social desirability bias. All of the participants were enrolled in a course taught by the researcher so this may have had an effect on the content of what the participants reported. In future research a sample of CITs could be used who are enrolled in a class section that is not taught by the researcher. A second limitation was the participants were all CITs from one Southern state. The findings are not necessarily representative of all CITs who are enrolled in online counselor education programs as there is the possibility that CITs in other regions and states would have different experiences. Future research should expand our data gathering in different states and regions.

\section{Conclusion}

The goal of this study was to understand the experiences of online CITs as they went into their local communities to determine if counseling skill development and multicultural awareness would be increased. The author maintains that creating experiential assignments is important to the success of teaching counselor skill development and building multicultural awareness for students. The participants in this research study reported similar results to prior studies in which students were required to join a group they were not familiar with. Even in an online counseling course, students can gain experiences in communities which helps them to be more comfortable when counseling with diverse populations. Counselor educators must prepare assignments for students to be reflective before, during, and after their multicultural experiences so students are more attentive and mindful during the assignment.

While this study supported much of the previous literature on the effect of experiential education and on the challenges associated with teaching multicultural awareness and counselor skill development in an online counseling environment, it also has a number of implications for counselor educators who teach in an online or hybrid program. First, counselor 
educators who teach students in online environments need to make extra efforts to include assignments which will take the students out of their comfort zones. Second, counselor educators need to be aware students who are enrolled in an online counselor education program may not get any actual experience interacting with diverse clients until their field experience classes (Practicum and Internship). The students who have an experience going out into their community before they enter their counseling field experiences are more likely to have a reduction of anxiety and an increased sense of self-efficacy when they do begin their counseling field experiences. Third, structuring the assignment so the students will know they need to be reflective before, during, and after the community immersion experience is crucial for the student to be able to be mindful of their experiences.

\section{Acknowledgements}

The author appreciates all study participants.

\section{References}

American Counseling Association. (2015). Multicultural and Social Justice Counseling Competencies. Retrieved from: http:www.counseling.org/knowledge-center/competencies

American School Counselor Association (2017). Ethical Standards for School Counselors. Retrieved from: https://www.schoolcounselor.org/school-counselors-members/legal-ethical.

Benshoff, J. M., \& Gibbons, M. M. (2011). Bringing life to e-learning: Incorporating a synchronous approach to online teaching in counselor education. Professional Counselor, 1(1), 21-28. https://doi.org/10.15241/jmb.1.1.21

Barbee, P. W., Scherer, D., \& Combs, D. C. (2003). Prepracticum service-learning: Examining the relationship with counselor self-efficacy and anxiety. Counselor Education \& Supervision, 43(2), 108-119. https://doi.org/10.1002/j.1556-6978.2003.tb01835.x

Burnett, J. A., Hamel, D., \& Long, L. L. (2004). Service learning in graduate counselor education: Developing multicultural counseling competency. Journal of Multicultural Counseling and Development, 32(3), 180-185. https://doi.org/10.1002/j.2161-1912.2004.tb00370.x

Burnett, J. A., Long, L. L., \& Horne, H. L. (2005). Service learning for counselors: Integrating education, training, and the community. Journal of Humanistic Counseling, Education, And Development, 44(2), 158-167. https://doi.org/10.1002/j.2164-490X.2005.tb00028.x

Cicco, G. (2013). Online course effectiveness: A model for innovative research in counselor education. Journal on School Educational Technology, 9(1), 10-16. https://doi.org/10.26634/jsch.9.1.2399

Commission on Rehabilitation Counselor Certification. (2017). Code of Professional Ethics for Rehabilitation Counselors. Retrieved from: https://www.crccertification.com/code-of-ethics-3

Farley, N. (2017). Improvisation as a meta-counseling skill. Journal of Creativity in Mental Health, 12, 115-128. https://doi.org/10.1080/15401383.2016.1191402

Irvine, N., \& Carmichael, P. (2009). Threshold concepts. Active Learning in Higher Education, 10(2), 103-119. https://doi.org/10.1177/1469787409104785

Ivey, A. E., Ivey, M. B., \& Zalaquett, C. P. (2010). Intentional interviewing \& counseling: Facilitating client development in a multicultural society ( $7^{\text {th }}$ ed.). Belmont, CA: Brooks/Cole.

Jett, S. T., \& Delgado-Romano, E. A. (2009). Prepracticum service-learning in counselor education: A qualitative case study. Counselor Education and Supervision, 49(2). 106-121. https://doi.org/10.1002/j.1556-6978.2009.tb00091.x

Kolb, A. Y., \& Kolb, D. A. (2005). Learning styles and learning spaces: Enhancing experiential learning in higher education. Academy of Management Learning \& Education, 4(2), 193-212. https://doi.org/10.5465/AMLE.2005.17268566

Lewis, M. L., Rappe, P. T., Albury, J. D., \& Edler, L. D. (2017). Creative teaching and reflection in nontraditional settings: Regional, national, and international experiences. Social Development Issues, 39(1), 29-40.

Minton, C. B., Morris, C. W., \& Yaites, L. D. (2014). Pedagogy in counselor education: A 10-year content analysis of $\begin{array}{lllll}\text { journals. } & \text { Counselor Education and }\end{array}$ https://doi.org/10.1002/j.1556-6978.2014.00055.x

Nakelet, O. H., Prossy, I., Bernard, O. B., Peter, E., \& Dorothy, O. (2017). Assessment of experiential learning and teaching approaches in undergraduate programmes at the School of Agricultural Sciences, Makerere University, Uganda. International Journal of Higher Education, 6(5), 155-167. https://doi.org/10.5430/ijhe.v6n5p155 
Oswald, G. R., Huber, M. J., Wilson, J. F., \& Embree, J. (2015). The status of technology-enhanced education and service delivery in rehabilitation counselor education. Rehabilitation Research, Policy, and Education, 29(3), 194-207. https://doi.org/10.1891/2168-6653.29.3.194

Servaty-Seib, H. L., \& Tedrick Parikh, S. J. (2014). Using service-learning to integrate death education into counselor preparation. Death Studies, 38(3), 194-202. https://doi.org/10.1080/07481187.2012.738774

Sherman, P., \& Boukydis, O. (2020). Framing undergraduate perspectives on experiential learning within Soka Education Theory. IAFOR Journal of Education, 8(3), 77-94. https://doi.org/10.22492/ije.8.3.05

Smith, M. M., Jennings, L., \& Lakhan, S. (2014). International education and service learning: Approaches toward cultural competency and social justice. The Counseling Psychologist, 42, 1188-1214. https://doi.org/10.1177/0011000014557499

Stewart, T., \& Mejía, X. (2011). Gay, lesbian, and bisexual issues in counselor education: The potential of service-learning in the development of sensitive and competent mental health professionals. In T. Stewart, N. Webster, T. Stewart, N. Webster (Eds.), Exploring cultural dynamics and tensions within service-learning (pp. 299-319). Charlotte, NC: IAP Information Age Publishing.

Toporek, R. L., \& Worthington, R. L. (2014). Integrating service learning and difficult dialogues pedagogy to advance social justice training. The Counseling Psychologist, 42(7), 919-945. https://doi.org/10.1177/0011000014545090

Yang, Y. C., \& Chou, H. (2008). Beyond critical thinking skills: Investigating the relationship between critical thinking skills and dispositions through different online instructional strategies. British Journal of Educational Technology, 39(4), 666-684. https://doi.org/10.1111/j.1467-8535.2007.00767.x 


\section{Appendix A}

\section{Experiential Community Immersion Assignment}

Spend some time with a group that you are not familiar with, and that makes you feel a little uncomfortable. As professional school counselors, you will need to be capable of working with a diverse population of students and their families.

Identifying and participating in a multicultural experience helps to gain knowledge, sensitivity, and skills needed to work with a diverse population effectively. Personal contact is a more robust way for counselors in training to increase their level of comfort with and to decrease their level of anxiety about individuals who are different from them.

The purpose of the assignment paper is to help you learn and grow. It is suggested that you choose one of the following multicultural groups to spend time with: Homeless or Near Homeless individuals, Asian Americans, African Americans, Hispanic Americans, Native Americans, Religious Minorities (Muslims, Jews), Refugees, Individuals with Disabilities, or LGBTQIA individuals.

Note: Your chosen group and plan for this assignment should be submitted in writing to the instructor by the end of the second week of the class for approval.

\section{$\underline{\text { Report Guidelines }}$}

Your reflection paper should contain the following:

1. Before the experience, describe your thoughts and feelings you had about immersing yourself in the chosen community.

2. During the experience, pay attention to your thoughts and feelings so you can include them in the reflection.

3. After the experience, describe the thoughts and feelings that you ended with.

This report should be well-written structurally and grammatically. It should follow the guidelines of the APA Publication Manual. Your paper should not exceed 2-3 typewritten pages (double-spaced). 


\section{Appendix B}

Figure 1

Distribution of Community Immersion Sites by Type

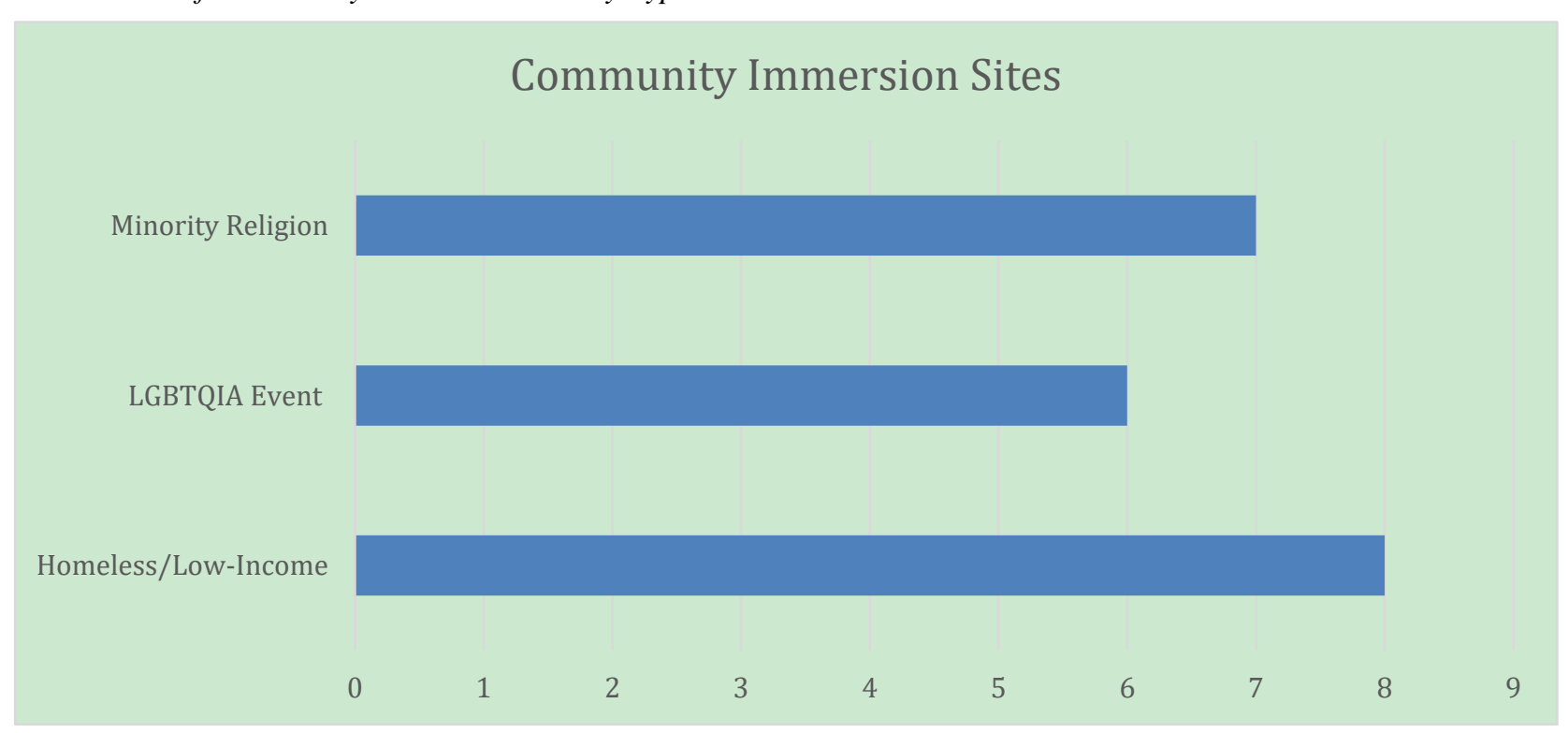




\section{Appendix C}

Table 1

Representation of Study Findings

Themes

Example Quotes

Pre-experience Reflections

Overwhelming Nervousness

"I have seen gay people on t.v. and they seemed fine. But now that I'm going to be around them, I can't help but feel nervous." (Jalissa, age 40)

Judgmental Thoughts

"I have always thought homeless people were dirty and lazy." (Amanda, age 32)

Active-experience Reflections

Welcoming Environment

Normalization of the Minority Population

"I felt welcomed when the people smiled at me and made eye contact. It made me feel much better."

(Sarah, age 35)

"I saw people that looked and acted in the same way that my friends and family life do." (Derek, age 33)

Post-experience Reflections

Similarities between Groups

"We've done the same type of work and like the same hobbies." (Erin, age 42)

Motivation to Create Relationships

"The only way to have a school where kids feel welcomed is if they know they are wanted and are important to the school." (Susan, age 31)

Increased Empathy

"I know I will work with kids who are gay. I want them to know I'm there for them if they get bullied at school. I want to be supportive." (Dee, age 21)

\section{Copyrights}

Copyright for this article is retained by the author(s), with first publication rights granted to the journal.

This is an open-access article distributed under the terms and conditions of the Creative Commons Attribution license (http://creativecommons.org/licenses/by/4.0/). 